\title{
Synthesis, Characterization and Curing Optimization of a Biobased Thermosetting Resin
}

\section{from Xylitol and Lactic Acid}

\section{Arash Jahandideh $^{1}{ }^{*}$, Kasiviswanathan Muthukumarappan ${ }^{1}$}

${ }^{1}$ Agricultural and Biosystems Engineering Department, South Dakota State University, PO Box 2120, Brookings, SD 57007, USA

* Corresponding author current address: Agricultural, Biosystems \& Mechanical Engineering Department, 1400 North Campus Drive Box 2120, Brookings, SD 57007, USA. Tel.: +1 (605) 6885670

Corresponding author: arash.jahandideh@sdstate.edu

\section{$\underline{\text { Abstract }}$}

A biobased thermoset resin was synthesized by direct condensation reaction of lactic acid with xylitol followed by the end-functionalization of the hydroxyl groups of branches by methacrylic anhydride. Chemical structures of resins were evaluated and confirmed by ${ }^{13} \mathrm{C}$ NMR and Fourier-transform infrared spectroscopy (FT-IR). Different techniques were employed for the optimization of the curing process. Techniques including Microscopy, Differential Scanning Calorimetry (DSC) and Dynamic Mechanical Thermal Analysis (DMTA) were employed for characterization of the cured resins. Thermogravimetric analyses (TGA) were also carried out to check the thermal stability of the cured resins. The viscosity of the neat resin was measured at different temperatures and different stress levels. Water adsorption tests were also carried out to check the water absorption properties of cured resins. The glass temperature (Tg) of the resin was $98^{\circ} \mathrm{C}$, and the viscosity of the resin was $2.97 \mathrm{~Pa}$ s at room temperature which drops to 0.07 Pa s upon increasing the temperature to $85^{\circ} \mathrm{C}$. The biobased content of the resin was calculated 
as $77 \%$. Cheap raw materials, high biobased content, biodegradability, good thermomechanical and rheological properties, good processability and good thermal stability are of advantages of the synthesized resin which makes the resin comparable with commercial unsaturated polyester resins.

Keywords:_synthesis; thermosets; crosslinking; renewable resources; lactic acid; thermal mechanical properties

\section{Introduction}

Due to a shortage of petroleum resources, ecological and economic concerns associated to petroleum based resins, different biobased raw materials have been suggested for production of biobased resins including vegetable oils [1-3], polyols and polyphenols [4, 5] and lactic and itaconic acid [6]. Poly lactic acid (PLA) is a biodegradable aliphatic polyester which is derived from lactic acid [7]. Versatile and economical renewable sources of lactic acid (LA), and biodegradability of the products makes LA a suitable source for production of bioplastics $[8,9]$. Thermoplasts are a class of polymers with high molecular weight where the chains are associated through intermolecular forces and their structure is weaken rapidly upon temperature increase. In contrast, thermosets form chemical bonds during the curing process and the structure cannot be reformed upon further heating-cooling processes $[9,10]$. Thermosets can be tailored for a desired property by changing cross-linking density or structure which makes them capable of being engineered for a certain functionality.

Limitations in impregnation of viscous matrix to fibers is a major problem in composites. Poor impregnation makes the production process to be slow and also reduces the mechanical strength of the composites $[11,12]$. Low viscosity of thermosets results in better processability 
and better impregnation of fibers making thermosets desirable as a matrix for reinforced composite applications [13]. In addition, PLA's hydrophobic nature makes it incompatible with natural fibers [14-16]. Hydrophilic fibers cannot be efficiently employed for reinforcing the PLA matrix as the adhesion of the fiber to the hydrophobic resin is poor which contributes to poor mechanical properties of the produced composites [17]. Several studies carried out to enhance the compatibility of the natural fibers in the matrix include treating the fibers with hydrophobic functional groups such as maleic anhydride [18, 19], ultrasonic and plasma treatment [20, 21] and co-polymerization of PLA with a more hydrophilic monomer like glycolic acid monomers [22].

Different studies have been performed on synthesis of LA based thermosetting resins suitable for different applications including structural composites, biomedical applications, drugdelivery applications, tissue engineering, coating applications or smart packaging. [22-28]. Recently, thermoset resins prepared by direct condensation of LA with glycerol [5], allyl alcohol terminated LA oligomers [25], and pentaerythritol [24] have been introduced for biocomposite productions. Star-shaped molecules resulted after direct condensation of the core molecule with LA were further functionalized with an end-capping agent [28]. It is presumed that more hydroxyl groups of the core molecule provide a better extended network of the final thermosets [29]. In addition, unsaturated hydroxyl groups of the core molecule may ultimately increase the hydrophilicity of the produced resin and make the resin more compatible with natural fibers which ultimately increases the mechanical properties of biocomposites produced from natural fibers and PLA thermoset.

In this study, the possibility of producing resins from LA and xylitol have been investigated. Thermoset resin was synthesized in a two-step synthesis procedure: a direct 
condensation-polymerization followed by an end-functionalization reaction. The structure of the resin was confirmed using ${ }^{13} \mathrm{C}$-NMR and FTIR. The curing process was optimized and the thermomechanical properties of cured resins was investigated using dynamic mechanical thermal analysis (DMTA), differential scanning calorimetry (DSC) and thermogravimetric analysis (TGA). The advantages of using xylitol as the core molecule are that 1) it is biobased and relatively inexpensive, 2) it lowers the viscosity of the final resin enhancing its processability, 3) xylitol has more hydroxyl groups providing a better extended network which results in better thermomechanical properties of the cured resin and 4) unsaturated branches of xylitol molecule, increase the hydrophilicity of the produced resin leading to a resin which is more compatible with natural fibers.

\section{Materials and Methods}

\subsection{Materials}

L (+)-lactic acid ( $\geq 90 \%$; Acros Organics) and xylitol ( $\geq 99 \%$; Sigma-Aldrich) were used as the main reactants. Toluene ( $\geq 99.8 \%$; Sigma-Aldrich) as the solvent, Methanesulfonic acid $(\geq 99.0 \%$; Sigma-Aldrich) as the catalysts, Hydroquinone ( $\geq 99.5 \%$; Sigma-Aldrich) as the inhibitor, Methacrylic anhydride ( $\geq 94 \%$; Sigma-Aldrich) as the end-functionalization agent were also used in synthesis. Benzoyl peroxide ( $\geq 98 \%$; Sigma-Aldrich) was used as the free radical initiator for crosslinking phase. Xylenes ( $\geq 98.5 \%$; Sigma-Aldrich) and Isopropyl alcohol (99.5\%; Sigma-Aldrich) were employed for the titration. Potassium hydroxide $(\geq 85 \%$; SigmaAldrich) solution in absolute ethanol was used as the titrant with phenolphthalein (1\% in ethanol, Fluka) as the indicator. 


\subsection{Synthesis}

The resin was synthesized by direct condensation reaction of LA with xylitol and further end-functionalizing of the hydroxyl groups of branches by methacrylic anhydride. Xylitol molecules played the role of a clustering agent in the final polymer structure. Eventually, a starshaped oligomer of xylitol and LA was prepared in the step-one reaction. In the step-two reactions, branches were end-functionalized with methacrylic anhydride. The chemical reactions and idealized structures are presented in figure 1.

\subsubsection{Step-one reactions: poly-condensation of LA with xylitol}

The first synthesis step was carried out employing a direct condensation polymerization technique in the presence of toluene as an auxiliary solvent for water removal. LA (1.5 moles) was added to 0.1 mole of xylitol diluted in $75 \mathrm{~g}$ of toluene containing $0.1 \% w t$ of the catalyst methanesulfonic acid (see figure 1). The components were transferred to a three-neck, roundbottom flask, equipped with a magnetic stirrer in which one neck was connected to a nitrogen flow and toluene reflux from and the azeotropic distillation apparatus. The other two necks were used for toluene reflux from an azeotropic distillation unit and connecting a thermometer. In the third neck, an azeotropic distillation unit was connected to a condenser for toluene recovery. The flow of the nitrogen in the system was ensured by employing a mini gas bubbler in the outlet of the condenser. The temperature inside the flask was set to $145^{\circ} \mathrm{C}$ for two hours and then increased to $165^{\circ} \mathrm{C}$ for seven hours.

\subsubsection{Step-two reactions: End functionalization of the Oligomers}


The oligomers resulted from condensation reactions would have reactive groups but yet, the groups are not reactive enough for a satisfactory cross-linking. The branches were further functionalized with methacrylic anhydride to improve their reactivity by adding carbon double bonds. The resulted resin was cooled to $90^{\circ} \mathrm{C}$ and $1 \%$ wt hydroquinone was added to the reaction mixture for stabilization as well as inhibiting unwanted cross-linking reactions and gelation. Under a constant stirring rate and nitrogen purge flow, 0.55 mole of methacrylic anhydride was added dropwise and the temperature was maintained at $90^{\circ} \mathrm{C}$ for four hours. The medium was then transferred to a drop-shaped glass flask connected to a rotary evaporator under partial vacuum conditions ( $\sim 10$ mbar, 1 hour at $60^{\circ} \mathrm{C}$ and two hours at $\left.90^{\circ} \mathrm{C}\right)$ to remove the residual toluene and released methacrylic acid. The chemical reactions and idealized structures are presented in figure 1.

\section{$\underline{2.3 \text { Curing optimization }}$}

The thermal curing was performed by a free-radical polymerization method which forms a rigid three dimensional network. Different curing methods were investigated to obtaining an optimal curing procedure including different initiators: resin ratios, applying different heat regimes, applying different temperatures and retention times, applying different pressures and also applying different cooling strategies. The aim of the curing optimization was to obtain completely cured samples with no cracks or bubbles with the desired mechanical properties. To avoid premature cracks, the dispersion of the curing agent in the form of a fine powder and in the form of dissolved in toluene were examined. For identifying the sufficient ratio of the initiator to the neat resin, curing was performed with different ratios of $0.5,1,1.5,2$ and 3 wt $\%$. For fully cured samples, a microscopy technique was applied for checking the samples to stablish the 
presence and cause of cracks and bubbles in the cast resins. Using the proper initiator to resin ratio, the temperatures in the range of 90 to $140^{\circ} \mathrm{C}$ for 20 minutes periods were applied for thermal curing. Three different post curing methods, called a, b and c, were investigated and effects of the methods on mechanical properties of the final samples were investigated. In method a, curing was started by heating samples from room temperature to $150^{\circ} \mathrm{C}$ at a heat rate of $5^{\circ} \mathrm{C} / \mathrm{min}$. Samples were kept at $150^{\circ} \mathrm{C}$ for 20 minutes and after curing, they were cooled at room temperature. In method $\mathrm{b}$, curing was started at $50^{\circ} \mathrm{C}$ for 10 minutes followed by another 10 minutes at $90^{\circ} \mathrm{C}$. Finally, samples were post cured at $150^{\circ} \mathrm{C}$ for 20 minutes and cooled and stored at room temperature. In method c, curing was started at $150^{\circ} \mathrm{C}$ in a preheated oven and continued for 20 minutes. After curing, samples were cooled and stored at room temperature. Completion of the curing processes were investigated by analyzing the DSC residual exotherms. Finally, mechanical strength of different cured samples cured via different techniques were evaluated through mechanical testing and the best curing method was identified.

\section{$\underline{2.4 \text { Characterization }}$}

The progress of the condensation reaction was monitored by titrating the residual carboxyl groups during the step-one resin synthesis. The conversion progress was determined by titrating aliquot samples $(1 \mathrm{~g})$ taken hourly during the condensation reaction. The samples were first diluted with $20 \mathrm{~mL}$ of $1: 1 \mathrm{v} / \mathrm{v}$ xylene/isopropyl alcohol solutions and then titrated with 0.5 $\mathrm{M} \mathrm{KOH}$ in absolute ethanol with phenolphthalein $1 \%$ as the indicator.

The chemical structure of step-one and step-two resins were determined with a Carbon

Nuclear Magnetic Resonance $\left({ }^{13} \mathrm{C}\right.$ NMR) spectrometry (Bruker BioSpin GmbH, Germany) at $400 \mathrm{MHz}$. Sample concentration in $5 \mathrm{~mm}$ tubes was $10 \%$ by weight in $\mathrm{CDCl}_{3}$ and the 
measurement temperature was $45^{\circ} \mathrm{C}$. The internal standard was tetramethylsilane, TMS, and the shifts were expressed in ppm.

IR spectra of step-one, step-two and cured samples were recorded at room temperature on Nicolete 6700 spectrometer, supplied by Thermo Fisher Scientific, Massachusetts, USA in the range of 4000-600 $\mathrm{cm}^{-1}$. Each spectrum was recorded after the sample was scanned 60 times.

Calorimetric analyses were carried out by a DSC on a TA Instrument Q 100 (V9.9 Build 303- supplied by Water LLC, New Castle DE) thermal analyzer. Samples of approximately 10 mg were sealed in aluminum hermetic pans and tested under a nitrogen atmosphere. The calorimeter was calibrated using an indium standard (heat flow calibration) and an indium- leadzinc standard (temperature calibration). Uncured resin was analyzed from $-20^{\circ} \mathrm{C}$ to $220^{\circ} \mathrm{C}$ at a heating rate of $10^{\circ} \mathrm{C} / \mathrm{min}$ in order to investigate the crosslinking reaction. Isothermal curing of resins was also performed at $90^{\circ} \mathrm{C}, 100^{\circ} \mathrm{C}, 120^{\circ} \mathrm{C}, 130^{\circ} \mathrm{C}, 140^{\circ} \mathrm{C}$ and $150^{\circ} \mathrm{C}$ for 20 minutes and residual exotherms were analyzed from $25^{\circ} \mathrm{C}$ to $200^{\circ} \mathrm{C}$ at a heating rate of $10^{\circ} \mathrm{C} / \mathrm{min}$.

Thermogravimetric analyses of the cured resins were carried out with a Q50 from a TA Instrument supplied by Waters LLC. Samples with an approximate mass of $10 \mathrm{mg}$ were heated from $30^{\circ} \mathrm{C}$ to $600^{\circ} \mathrm{C}$, at a heat rate of $10^{\circ} \mathrm{C} / \mathrm{min}$ under a $\mathrm{N}_{2}$ purge gas stream of $20 \mathrm{~mL} / \mathrm{min}$. Weight percent data versus time was plotted.

Dynamic Mechanical Thermal Analysis was performed on cured samples from different methods on a DMTA (Q800 from TA Instruments, supplied by Waters LLC). The tests were performed on samples with dimension of approximately $60 \times 15 \times 3 \mathrm{~mm}$ from $-20^{\circ} \mathrm{C}$ to $150^{\circ} \mathrm{C}$ in a dual cantilever bending mode with a heat rate of $5^{\circ} \mathrm{C} / \mathrm{min}$; the frequency was $1 \mathrm{~Hz}$, the amplitude was $15 \mu \mathrm{m}$ and the tests were performed under a nitrogen atmosphere. 
The viscosity of the uncured resin was determined using a viscoanalyzer rheometer (TA instrument, Sweden). All measurements were done with a truncated cone plate configuration $\left(\varnothing 15 \mathrm{~mm}, 5.4^{\circ} \mathrm{C}\right)$. Viscosities of uncured resins were measured in a temperatures range of 25 to $85^{\circ} \mathrm{C}$ in increments of $10^{\circ} \mathrm{C}$. Shear stress ranged from 0.2 to $400 \mathrm{~Pa}$.

\section{$\underline{2.5 \text { Water adsorption tests }}$}

The water adsorption tests were carried out based on ASTM D 570-98 standard to determine the relative rate of absorption of water by the cured samples when immersed. The dimension of test specimens were $60 \times 60 \times 1 \mathrm{~mm}$. The tests were perform in 3 modes: LongTerm Immersion, Two-Hour Boiling Water Immersion and Immersion at $50^{\circ} \mathrm{C}$. In Long-Term

Immersion, the specimens were placed in a container of distilled water maintained at a temperature of $23 \pm 1^{\circ} \mathrm{C}$ and the total water absorbed by samples versus time were measured. In the two-hour-boiling-test, adsorption of samples was measured after $120 \mathrm{~min}$ of immersion, in the boiling distilled water and in Immersion at $50^{\circ} \mathrm{C}$ mode, water adsorption was measured at a temperature of $50^{\circ} \mathrm{C}$ for different time intervals.

\section{Results and discussion}

\section{$\underline{3.1 \text { Titration }}$}

The proper condensation-reaction time is essential, as insufficient reaction time results in unreacted reactants and excessive reaction time results in transesterification reactions which degrades the structure [5]. The ratio of the reacted to initial carboxylic groups in the polymerization-condensation step is related to the degree of completion of the condensation 
reaction in the polymerization-condensation step. In this step, - $\mathrm{COOH}$ groups are reacting with the $-\mathrm{OH}$ groups of xylitol core molecules (see figure 1). As the reaction proceeds, the $-\mathrm{COOH}$ groups react and the length of LA arm increases. The number of carboxylic groups was measured with an acid-base titration method $[30,31]$. The solvent system was chosen based on ASTM D974. The conversions during the first 720 minutes of the reaction were calculated based on the $\mathrm{mL}$ of consumed $\mathrm{KOH}$ by the $1 \mathrm{~g}$ samples. From figure 2, it can be seen that the reaction started almost after 100 minutes. The conversion reaction proceeds rapidly during the next 320 minutes. The reaction continues until 720 minutes and after that the conversion rate did not change due to transesterification reactions. Based on the titration results, a 12 hours condensation reaction period was considered for the first-step reaction which results in a $94 \%$ conversion of the carboxylic groups. Bakare et al. employed a similar acid-base titration method for measuring the degree of reaction of LA with glycerol and reported 95\% reaction competition after 360 minutes [5]. The less reaction times required for LA- glycerol reaction compared to that of LA-xylitol reaction can be explained by the differences between the number of hydroxyl groups in glycerol and xylitol.

\section{$\underline{3.2}{ }^{13}$ C-NMR spectroscopic analysis}

The NMR analysis was performed to confirm the chemical structure of the step-one and step-two resins and also for measuring the obtained LA chain length. The ${ }^{13} \mathrm{C}-\mathrm{NMR}$ spectra of the step-one and end-capped resins are shown in figure 4. The expected and observed chemical shifts and assignments are shown in table 1. Shifts for different carbon environments have been assigned based on data from the literature $[5,24,25,31,32]$ Carbon environments for the ideal structures of step-one and step-two resins are presented in figure 3a. and 3b., respectively. As it 
can be seen in figure 3a. for the step-one resin, 9 different carbon environments were expected: $\mathrm{A}_{1,2}$ for methyl groups, $\mathrm{B}_{1-4}$ for $\mathrm{CHs}$ adjacent to different groups (shown in table 1), $\mathrm{C}_{1,2}$ for carbonyl groups and the $\mathrm{CH}_{2}\left(\mathrm{~B}_{4}, \mathrm{~B}_{5}\right)$ in the central xylitol structure.

The number of expected chemical shifts would be even greater in the end-capped resins case as the chemical structure is more complex. Apart from chemical shifts of methyls (A), CHs (B) and carbonyls (C), another chemical shift for $\mathrm{C}=\mathrm{C}$ bond is also expected.

In the carbonyl area $(160-180 \mathrm{ppm})$ [25], two peaks for the carbonyl groups of LA were expected: $\mathrm{C}_{1}$ for the main-chain carbonyl $\mathrm{C}=\mathrm{O}$ and $\mathrm{C}_{2}$ for $\mathrm{LA}$ carbonyl group adjacent to the $\mathrm{O}-\mathrm{CH}_{2}-$ branch of the xylitol core molecule which both of them were clearly raised at 169.59 $\left(\mathrm{C}_{1}\right)$ and $169.89\left(\mathrm{C}_{2}\right)$ [25]. Also, another weak peak was observed in the step-one resin at 174.80 ppm which can be assigned to $\mathrm{C}=\mathrm{O}$ of the LA end-group, for the remaining unreacted LA [5, 7].

For the end-capped resin however, in the carbonyl area, the signal is broad, as LA carbonyls next to the xylitol core molecule, and next to the methacrylic end, will give different signals compared to a LA carbonyl next to another LA component (Fig 4b.). In addition, another carbonyl group belongs to a methacrylic end-group is also expected which can be seen at 166.57 ppm. Another weak peak was also observed at $171.19 \mathrm{ppm}$ which can be assigned to carbonyl of methacrylic acid, released during the end-capping reactions. The weak peak which is seen at $163.18 \mathrm{ppm}$ is corresponded to carbonyl groups of methacrylic anhydride [10].

The chemical shifts for carbon atom adjacent to an oxygen atom would be in the range of 60-75 ppm [31]. CH groups of xylitol core molecules showed signals in range of 68 ppm to 71 ppm- the $\mathrm{CH}$ next to the reacted LA carbonyl group and an oxygen atom gives a broad signal from 68 ppm to $71 \mathrm{ppm}\left[31\right.$ ] and it is assigned as $\mathrm{B}_{2,3}$ and $\mathrm{B}_{\sim 6}$. $\mathrm{B}_{4}$ and $\mathrm{B}_{5}$ peaks represent the $\mathrm{CH}$ groups in the xylitol core molecule with chemical shifts of $68.7 \mathrm{ppm}$ and $70.2 \mathrm{ppm}$, respectively. 
The $\mathrm{CH}$ adjacent to the hydroxyl end-group, $\mathrm{B}_{1}$, gives a signal at $66.61 \mathrm{ppm}$. The $\mathrm{CH}_{2}$ group in the xylitol core group can be seen as a weak peak at $68.71 \mathrm{ppm}$ [30]. No signal was detected around $64.4 \mathrm{ppm}$ for the $\mathrm{CH}_{2}$ group of unreacted xylitol molecules suggesting that the reaction of xylitol molecules and LA molecules was complete.

The LA methyl groups were detected in the 16-22 ppm range [15]. The hydroxyl functionalized end-group of methyl groups, $A_{1}$, are present in the step-one resin and were detected at $20.28 \mathrm{ppm}$. The $\mathrm{CH}_{3}$ groups in the LA chains, $\mathrm{A}_{2}$, were also detected in the range of 16.59-16.67 ppm [31]. The same signals were identified in the end-capped resin for the $A_{2}$ position. Absence of the $A_{1}$ signal in the step-two resins, indicates that the end-functionalization reactions were complete. The methyl groups of methacrylate in the end-capped resins $A_{3}$, were detected at a range of $17.83-18.07 \mathrm{ppm}[19]$.

The olefinic carbon sites, $\mathrm{D}_{1}$ and $\mathrm{E}_{1}$, presented in the methacrylated end-groups give signals in range of 126-127 ppm and 135-136 ppm. In addition, presence of free methacrylic acid, which is formed during the end-capping reaction was confirmed by observing the signal at 129.2 ppm which belongs to the olefinic carbon [20].

The NMR analysis confirmed that oligomers from the first synthesis step mainly have alcohol end-groups. The reaction of xylitol and LA was also confirmed, because there was no evidence of carboxylic acid groups in the NMR spectrum of the step-one resin. The length of the xylitol-LA chains was estimated based on the carbonyl peak areas based on the method described by Bakare et al [25]. The percentage of the LA in forms of reacted with the xylitol and in form of LA reacted in to free oligomers were also calculated based on the same method. From the peak areas of the LA end-groups at $169.59 \mathrm{ppm}$ and the main-chain lactic acid components at 170.8 ppm, the average chain length of the branches was estimated as around three lactic acid units. 
The branch lengths was measured as 3.3 LA and the percentage of LA reacted to oligomers or lactide was $14 \%$. The percentage of lactic acid reacted with xylitol was measured to be $82.3 \%$ and the percentage of chain ends reacted with methacrylic anhydride was $86.7 \%$. The reaction of methacrylic anhydride with the alcohol groups of chains was confirmed by detecting the corresponding signals.

\section{$\underline{3.3 \text { FTIR spectroscopy analysis }}$}

The FTIR analysis was applied for further analysis of the synthesized resins. Figure 5, shows the FTIR spectra of step-one, step-two and cured samples. The spectra of the first synthesis step shows a signal at $3500 \mathrm{~cm}^{-1}$ which can be attributed to an alcohol end-group [5, 25, 31]. As expected, this group is not presented in methacrylic anhydride functionalized resins where hydroxyl end groups were reacted with methacrylic anhydride. The peak for the $\mathrm{CH}$ group bond around $2990 \mathrm{~cm}^{-1}$ [31] can be found in all three spectra; while cured resins show two peaks in the carbonyl range $1740-1750 \mathrm{~cm}^{-1}$ which indicates two different $\mathrm{C}=\mathrm{O}$ groups in the structure [5, 31]. The presence of signals which correspond to carbon-carbon double bonds at $1635 \mathrm{~cm}^{-1}$ (stretching $\mathrm{C}=\mathrm{C}$ ) [5] and $815 \mathrm{~cm}^{-1}$ (bending $\mathrm{CH}_{2}$ ) [33] confirm that the end functionalization by the methacrylic anhydride did occur. These bonds are not present in stepone resin spectra. In addition, disappearance of signals related to $\mathrm{C}=\mathrm{C}$ bond in the cured resin spectra and an increase in the bond $-\mathrm{CH}$ stretching from 2850 to $3000 \mathrm{~cm}^{-1}$ indicates that the crosslinking reaction did occur [5, 25].

\section{$\underline{3.4 \text { Biobased content }}$}


The biobased content of the resin was calculated based on ASTM D6866 standard using the following formula:

$$
\begin{gathered}
\text { Biobased content }=\frac{\text { biobased carbon content }}{\text { total carbon content }} \times 100 \\
=\frac{X_{m}+L A_{m}-W_{m}}{X_{m}+L A_{m}-W_{m}+M A A_{m}-M A_{m}} \times 100
\end{gathered}
$$

Where, $X_{m}$ is the weight of Xylitol core molecule, $L A_{m}$ is the weight of LA, $W_{m}$ is the weight of released water during condensation polymerization. $M A A_{m}$ is the weight of methacrylic anhydride and $M A_{m}$ is the weight of the released methacrylic acid during the end-capping reactions [25].

$$
\begin{aligned}
& \mathrm{C}_{5} \mathrm{H}_{12} \mathrm{O}_{5}+15 \mathrm{C}_{3} \mathrm{H}_{6} \mathrm{O}_{3} \longrightarrow \mathrm{C}_{50} \mathrm{H}_{72} \mathrm{O}_{35}+15 \mathrm{H}_{2} \mathrm{O} \\
& \mathrm{C}_{50} \mathrm{H}_{72} \mathrm{O}_{35}+{ }_{5} \mathrm{C}_{8} \mathrm{H}_{10} \mathrm{O}_{3} \longrightarrow \mathrm{C}_{70} \mathrm{H}_{92} \mathrm{O}_{40}+5 \mathrm{C}_{4} \mathrm{H}_{6} \mathrm{O}_{2}
\end{aligned}
$$

Bio based content is found to be $76.7 \%$.

\subsection{Curing optimization}

Presence of cracks in casted resins dramatically reduces the mechanical strength of the matrix [34]. The proper mix ratio, severity of mixing, applied mixing method and mix temperatures would affect final distribution and propagation of cracks [35-37]. Improper mix ratio of the curing agent and resins results in higher exotherms, faster gelation and subsequently more shrinkage due to excessive thermal zoning (or hot spots) during the curing process [38, 39]. Investigating different mix ratios, demonstrates that $1 \% w t$ curing agent was proper for the synthesized resin. However, poor dispersion of solid state benzoyl peroxide results in benzoyl peroxide rich areas causing different rates of curing within the mixed product and subsequently, initiation of cracks. In other words, gradients in concentration of the hardener causes 
microcracks to be initiated during gelation phase which develop as the material cures or during thermal cycling [40].

Figure 6a. shows the initiation of cracks in the cured samples. As it can be seen, the cracks can occur due to presence of bubbles. However, propagation of the cracks can also be terminated when they reach the microbubbles (figure 6b.) as well as another crack propagating in the other direction (figure 6a.). The twofold effect of the bubbles can be better seen in figure 6c. were the microcrack is been initiated from one micro bubble and is also terminated at the other end by colliding with another microbubble. It can be seen in the figure $6 \mathrm{~d}$. that presence of benzoyl peroxide solid particles results in the initiation of cracks. When curing agent was added in form of powder, micro particles are inevitable. This problem was overcome by dissolving the curing agent in a solvent and mixing the solvent with the matrix at elevated temperatures (up to $50^{\circ} \mathrm{C}$ ) for better mixing.

The presence of bubbles in the casted samples was another problem which reduces the mechanical strength of the product and causes microcracks. Uncured resins were kept at ambient temperature under partial vacuum (20 millibars) for an hour which resulted in evaporation of the added solvent as well as eliminating the bubbles in the matrix. By changing the mixing method, applying partial vacuum and implementing a stage curing technique, the cracking and bubble problems were fully resolved.

\subsection{Differential Scanning Calorimetry}

DSC technique is currently applied to investigate curing of resins by detecting crosslinking reaction exotherms as well as residual exotherms of cured samples at different temperatures $[13,23,41]$. Figure 7 presents the exothermic heat reaction of the curing reaction. 
From the thermogram, it was observed that the resin cured between $100^{\circ} \mathrm{C}$ and $140^{\circ} \mathrm{C}$, (revealing an exothermic peak). The reaction heat was measured as $275.5 \mathrm{~J} / \mathrm{g}$, and the peak temperature was $117.25^{\circ} \mathrm{C}$. The onset temperature is defined as the intersection of the tangent of the peak with the extrapolated baseline, and measured as $108.10^{\circ} \mathrm{C}$. Bakare et al. reported a curing temperature range of $80^{\circ} \mathrm{C}$ to $130^{\circ} \mathrm{C}$ with exothermic heat evolved at $227.4 \mathrm{~J} / \mathrm{g}$ for a glycerol-LA thermoset resin with a length chain of 3 LAs [5]. In a more recent study, a curing temperature range of $90^{\circ} \mathrm{C}$ to $150^{\circ} \mathrm{C}$ and a heat of reaction of $194 \mathrm{~J} / \mathrm{g}$ for an allyl alcohol-LA resin was reported [25].

The peak exotherms in figure 7a. present the residual exotherms of DSC analysis from $25^{\circ} \mathrm{C}$ to $200^{\circ} \mathrm{C}$ at a heating rate of $10^{\circ} \mathrm{C} / \mathrm{min}$ for resin samples cured at $90^{\circ} \mathrm{C}, 100^{\circ} \mathrm{C}, 110^{\circ} \mathrm{C}$, $120^{\circ} \mathrm{C}, 130^{\circ} \mathrm{C}, 140^{\circ} \mathrm{C}$ and $150^{\circ} \mathrm{C}$ for 20 minutes. Presence of substantial residual heat in the DSC curves is an evidence showing that samples cured at temperatures below $110^{\circ} \mathrm{C}$ did not cured completely. However, there is a substantial reduction in exotherms of samples cured at temperatures above $110^{\circ} \mathrm{C}$ which is explained as the onset temperature of the resin was measured as $108.1^{\circ} \mathrm{C}$. The residual exotherms were also shifted to higher temperatures for samples cured at $120^{\circ} \mathrm{C}, 130^{\circ} \mathrm{C}$ and $140^{\circ} \mathrm{C}$. The absence of residual exotherms for samples cured at $150^{\circ} \mathrm{C}$ for 20 minutes, indicates that the curing reaction is fully completed. Therefore, in this study, the post curing conditions for curing was selected as 20 minutes at $150^{\circ} \mathrm{C}$.

\subsection{Thermogravimetric analysis}

Oxidative temperature is a measure of thermal stability. Higher oxidation temperature is associated with better overall quality of the tested products [1]. The degradation in thermoset systems, occurs after decomposition of the crosslinked polymer network as well as the random 
scission of the linear chains [32]. In this study, the TGA was performed to check the thermal stability of resins by recording the percentage weight loss of the cured samples versus time. The sample was heated from $30^{\circ} \mathrm{C}$ to $600^{\circ} \mathrm{C}$, at the uniform heat rate of $10^{\circ} \mathrm{C} / \mathrm{min}$ in a $\mathrm{N}_{2}$ gas purge stream of $20 \mathrm{~mL} / \mathrm{min}$. The thermogravimetric curves of cured resin at $150^{\circ} \mathrm{C}$ for 20 minutes is presented in figure 8 . The degradation occurred in the temperature region of $170^{\circ} \mathrm{C}$ to $462^{\circ} \mathrm{C}$. The maximum rate of decomposition which indicates the maximum rate of oxidation was observed at $380^{\circ} \mathrm{C}$. The char weight percent was $3.6 \%$ wt and the appearance of weak multiple peaks is an evidence for the presence of volatile substances in the resin.

\subsection{Dynamic Mechanical Thermal Analysis}

DMTA was performed to characterize the crosslinked resins, cured via different methods. There is evidence that stage curing increased mechanical properties of cured samples as it allows gradual solidification which results in a more relaxed state with less built in stresses [42]. Figure 9a. shows the storage modulus $\mathrm{G}^{\prime}$ in the temperature range of $-20^{\circ} \mathrm{C}$ to $150^{\circ} \mathrm{C}$ for samples cured by the different methods. The measured storage modulus with standard deviations at $25^{\circ} \mathrm{C}$ are given in table 2 . The storage modulus is related to the molecular packing density in the glassy state $[27,42]$. Storage modulus curves in figure $9 \mathrm{a}$. show that the resin cured with method b has a higher storage modulus than all other analyzed resins. Therefore, better mechanical properties are expected for the resins cured with this method. Due to the free movement of the polymer chain in the rubbery plateau region [23], the storage modulus of samples decreases in this temperature interval. The temperature range for major changes in storage modulus for method b cured resins is observed between $48^{\circ} \mathrm{C}$ and $83^{\circ} \mathrm{C}$. This interval for resins cured with method a was $36^{\circ} \mathrm{C}$ to $75^{\circ} \mathrm{C}$ showing that stage curing was effective for increasing mechanical properties. 
Figure 9b. shows the loss modulus G" curves for the samples cured with different methods and in table 2 the loss modulus of different samples at $25^{\circ} \mathrm{C}$ is given. The loss modulus is broader and shorter in samples cured with method $b$, suggesting better mechanical properties. The rather low value of the loss modulus was due to the rubbery plateau state of the cured resin and indicates the strong tendency for reversibility in the samples [23].

Figure 9c. shows the tan $\delta$ curves for the samples cured by the different methods and in table 2, peaks of $\tan \delta$ for the different cured resins are presented. The tan $\delta$ peaks were recorded at $93^{\circ} \mathrm{C}, 98^{\circ} \mathrm{C}$ and $95^{\circ} \mathrm{C}$ for resins cured via method a, b and c, respectively. The higher $\tan \delta$ peak values for resins cured with method $b$ indicates better mechanical properties. The tan $\delta$ peak for thermoplast PLA was reported at $50^{\circ} \mathrm{C}$ [14]. However, in LA based thermoset systems, $\tan \delta$ values would be comparably higher. Åkesson et al. reported a $\tan \delta$ of $83^{\circ} \mathrm{C}$ for a synthesized resin from pentaerythritol and LA. The observed $\tan \delta$ for a Glycerol-LA thermoset resins was observed at $97^{\circ} \mathrm{C}$ [5]. In addition, the tan $\delta$ value is believed to shift to higher temperatures after applying reinforcement fibers. The better adhesion of the fiber to the matrix generally results in the higher $\tan \delta$ value and better mechanical properties [23, 32].

\section{$\underline{3.9 \text { Viscosity measurements }}$}

The viscosity for thermoset resins is of importance because the resin must flow around and impregnate the reinforcement [11]. The viscosity of the resin was monitored using stress viscometry at temperatures $25^{\circ} \mathrm{C}, 35^{\circ} \mathrm{C}, 45^{\circ} \mathrm{C}, 55^{\circ} \mathrm{C}, 65^{\circ} \mathrm{C}, 75^{\circ} \mathrm{C}$ and $85^{\circ} \mathrm{C}$ and is presented in figure 10. The resin has a viscosity of $2.97 \mathrm{~Pa}$ s which drops to $0.06 \mathrm{~Pa}$ s upon increasing the temperature to $85^{\circ} \mathrm{C}$. Åkesson et al. previously reported a viscosity of $7000 \mathrm{~Pa} \mathrm{~s}$ at room temperature and $4 \mathrm{~Pa} \mathrm{~s}$ at $80^{\circ} \mathrm{C}$ for a four armed, star-shaped oligomer, synthesized by reacting 
pentaerythritol with LA [24]. The high viscosity at room temperature makes the resin unsuitable for impregnation of to the fiber reinforcement by the resin, even at elevated temperatures [11]. In a more recent study, Bakare et al. synthesized a glycerol-LA resin with a better processability at room temperature with a viscosity of $1.09 \mathrm{~Pa}$ s and $0.04 \mathrm{~Pa}$ s at temperatures above $100^{\circ} \mathrm{C}$ [5].

\subsection{Water adsorption tests}

The moisture content of a polymer affects its properties such as electrical insulation resistance, dielectric losses, mechanical strength, appearance, and even its dimensions. Diffusion of water into polymer matrix is a function of the square root of immersion time, type of water exposure, dimensions and shape of the specimen, and inherent properties of the plastic [43]. In

this study, the water adsorption tests were performed to determine the effects of exposure to water on water absorption rate of cured samples based on ASTM D 570-98. In the performed tests, samples with water adsorption rates of less than $1 \%$ or $5 \mathrm{mg}$ between intervals, were considered as substantially saturated, and the duration time that it took the samples to reach the saturation state was considered the water saturation time. The water saturation time is dependent on specimen thickness and the difference between the substantially saturated weight and the dry weight was reported as the water absorbed.

Figure 11a. presents the percent of absorbed water versus immersing time at $50^{\circ} \mathrm{C}$. For long-term immersion, the increase in weight was reported as a function of the square root of immersion time- presented in figure $11 \mathrm{~b}$. The initial slope of the graph is proportional to the diffusion constant of water in the matrix which is 0.252 and 0.699 at $23^{\circ} \mathrm{C}$ and $50^{\circ} \mathrm{C}$, respectively. The water saturation for long-term immersion at $23^{\circ} \mathrm{C}$ was $504 \mathrm{~h}$. The water saturation for immersion at $50^{\circ} \mathrm{C}$ was $110 \mathrm{~h}$. Percentage water adsorbed after saturation of $50^{\circ} \mathrm{C}$ 
immersion and Long term immersion at $23^{\circ} \mathrm{C}$ were $14.02 \pm 0.35$ and $8.08 \pm 0.61 \%$, respectively. Saturated water adsorption based on Two-Hour Boiling Water Immersion was $7.27 \pm 0.42 \%$.

\section{Conclusion}

In this study, a biobased thermoset resin was synthesized by poly-condensation of LA and xylitol followed by end-functionalization of branches with methacrylic anhydride. Chemical structure of resins were confirmed employing ${ }^{13} \mathrm{C}$ NMR and FTIR techniques. The resins were thermally cured employing a free-radical polymerization strategy. Different curing strategies and techniques were investigated for optimization and characterization of the curing process. Thermogravimetric analyses of the cured resin was also carried out to check the thermal stability of the cured resins. The viscosity of neat resins was measured at temperatures in the range of $25^{\circ} \mathrm{C}$ to $85^{\circ} \mathrm{C}$. It is observed that at room temperature the resin has a viscosity of $2.969 \mathrm{~Pa} \mathrm{~s}$ which drops to $0.056 \mathrm{~Pa} \mathrm{~s}$ upon increasing the temperature to $85^{\circ} \mathrm{C}$. Finally, water adsorption tests were carried out to check the water absorption properties of cured resins. Water absorbed percentage after saturation for $50^{\circ} \mathrm{C}$ immersion and Long term immersion at $23^{\circ} \mathrm{C}$ were 14.02 \pm 0.35 and $8.08 \pm 0.61 \%$, respectively. Saturated water adsorption after Two-Hour Boiling Water Immersion was $7.27 \pm 0.42 \%$. The synthesized thermoset resin showed a Tg, substantially higher than that of thermoplast PLA, at $98^{\circ} \mathrm{C}$. The biobased content of the resin was calculated as 76.7\%. High biobased content of the structure, good thermomechanical and rheological properties and good thermal stability are of advantages of the synthesized resin.

\section{$\underline{5 \text { Acknowledgement }}$}


The authors would like to acknowledge the funds provided by Agricultural Experiment Station, South Dakota State University and North Central Sun Grant via Department of Energy, Colorado in support of this research work. 

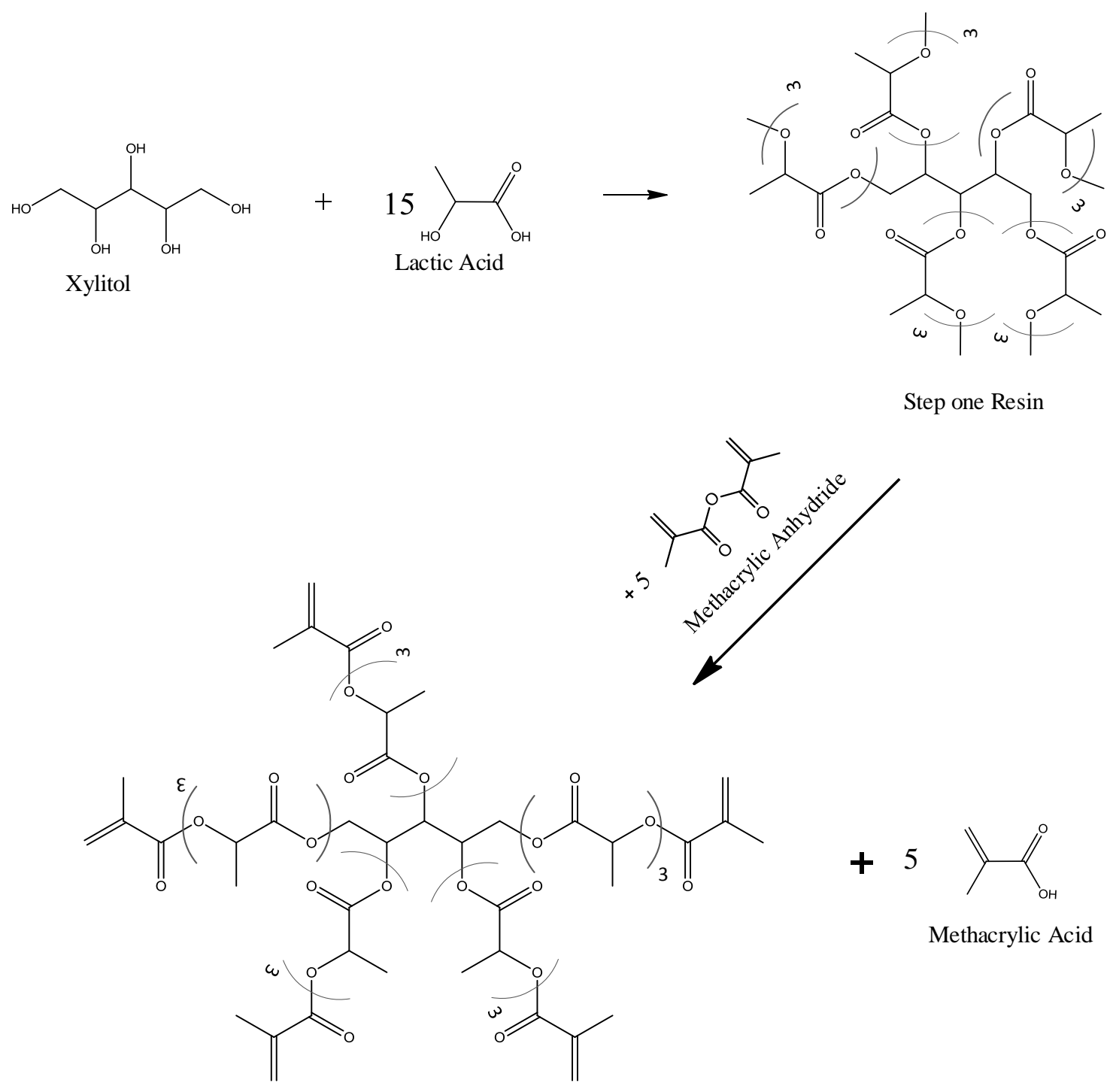

Step two Resin

Figure 1. Reaction scheme for the two-stage synthesis of methacrylate functionalized xylitol-LA resins with LA chain of 3 


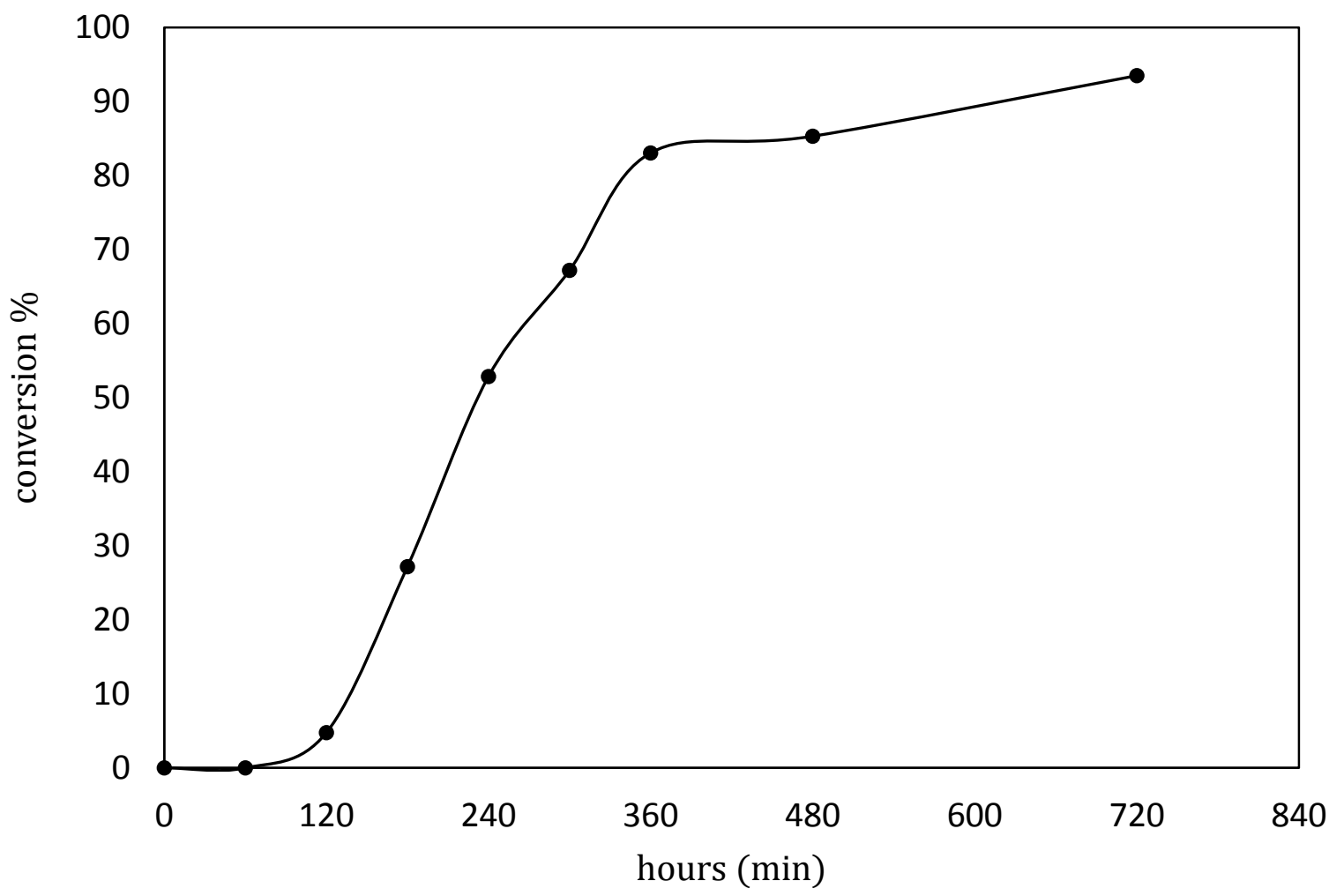

Figure 2, Conversion of carboxyl groups in poly condensation reaction 

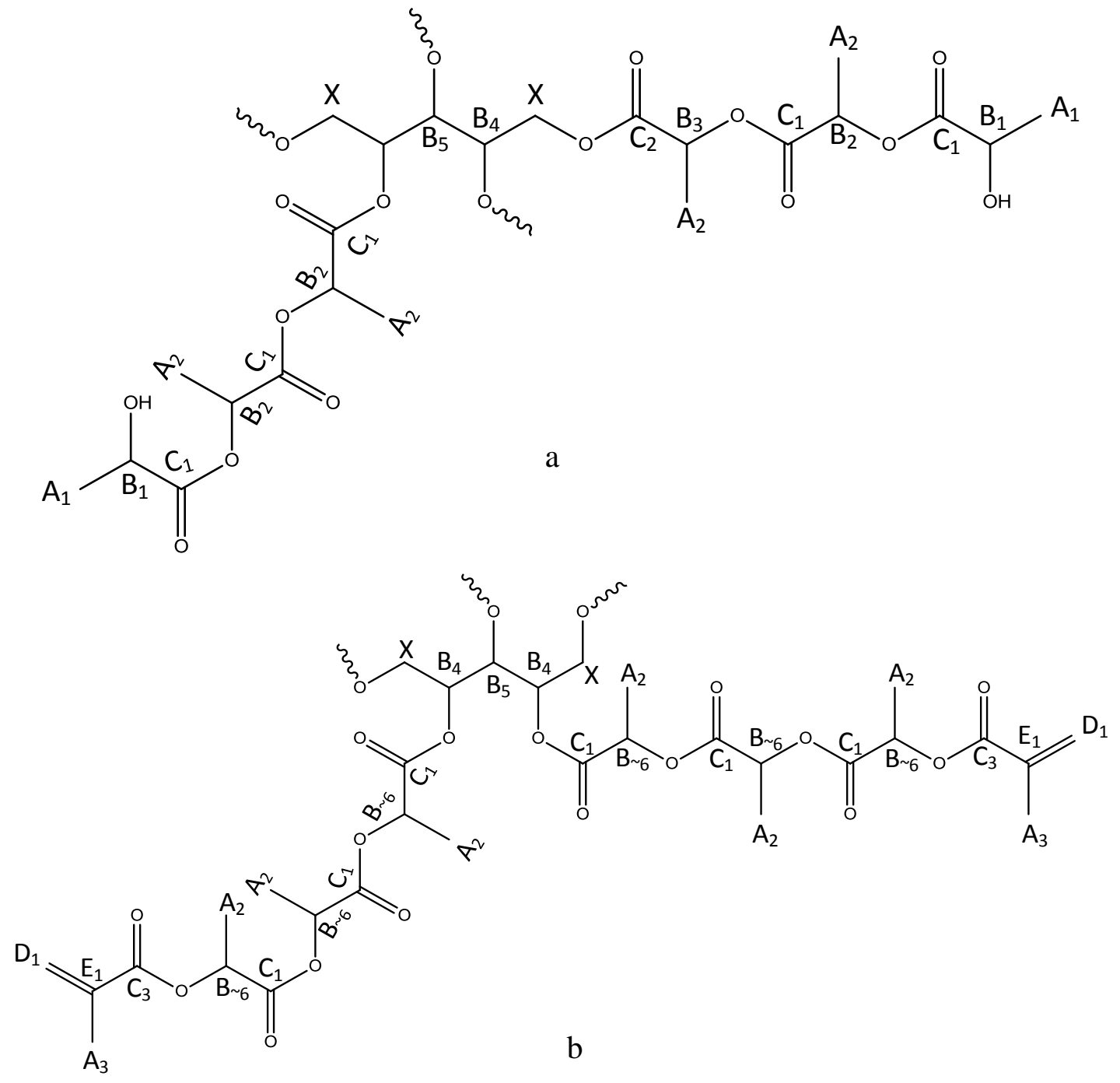

Figure 3, Carbon environments for the ideal structures of a) step-one and b) step-two resins 

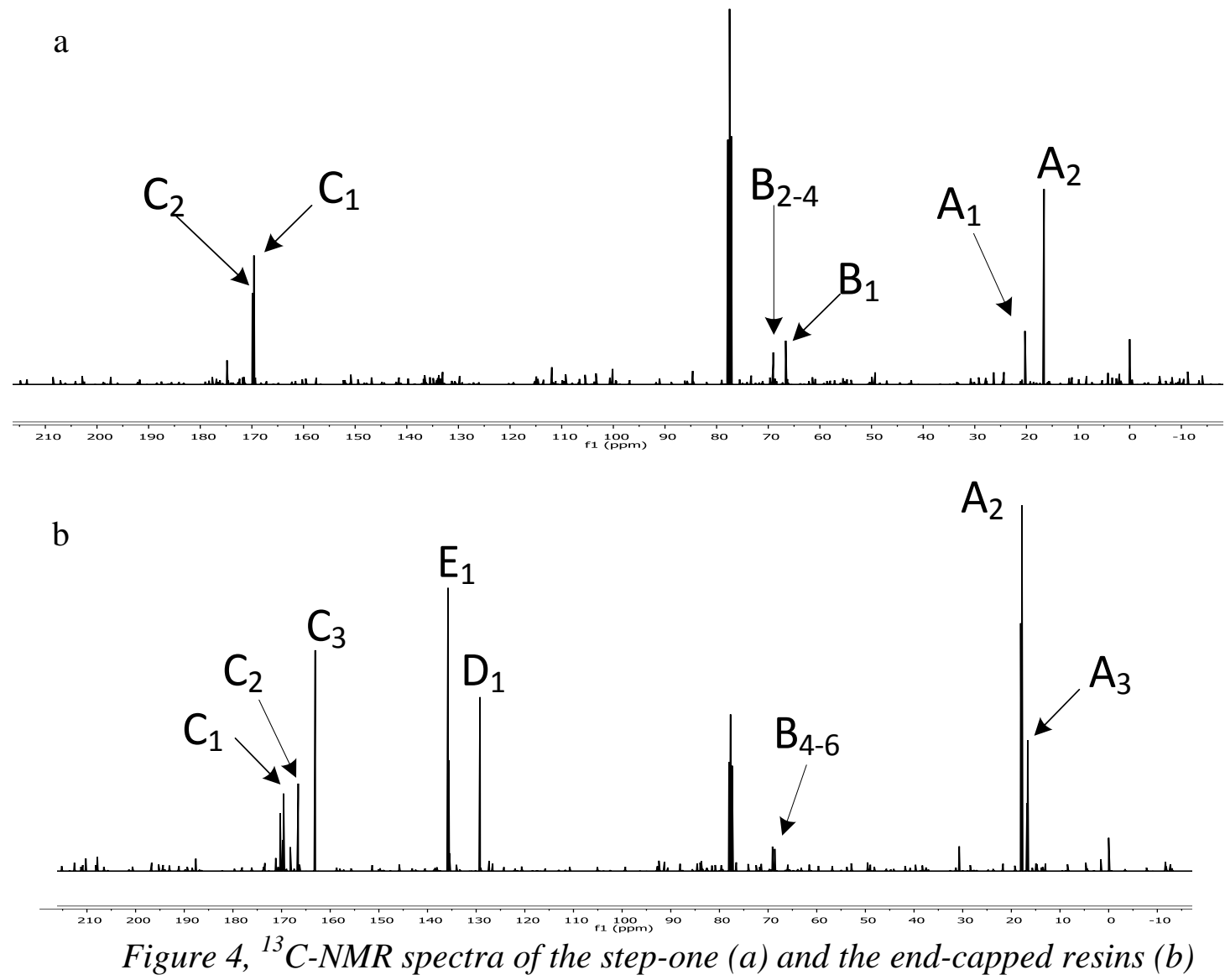


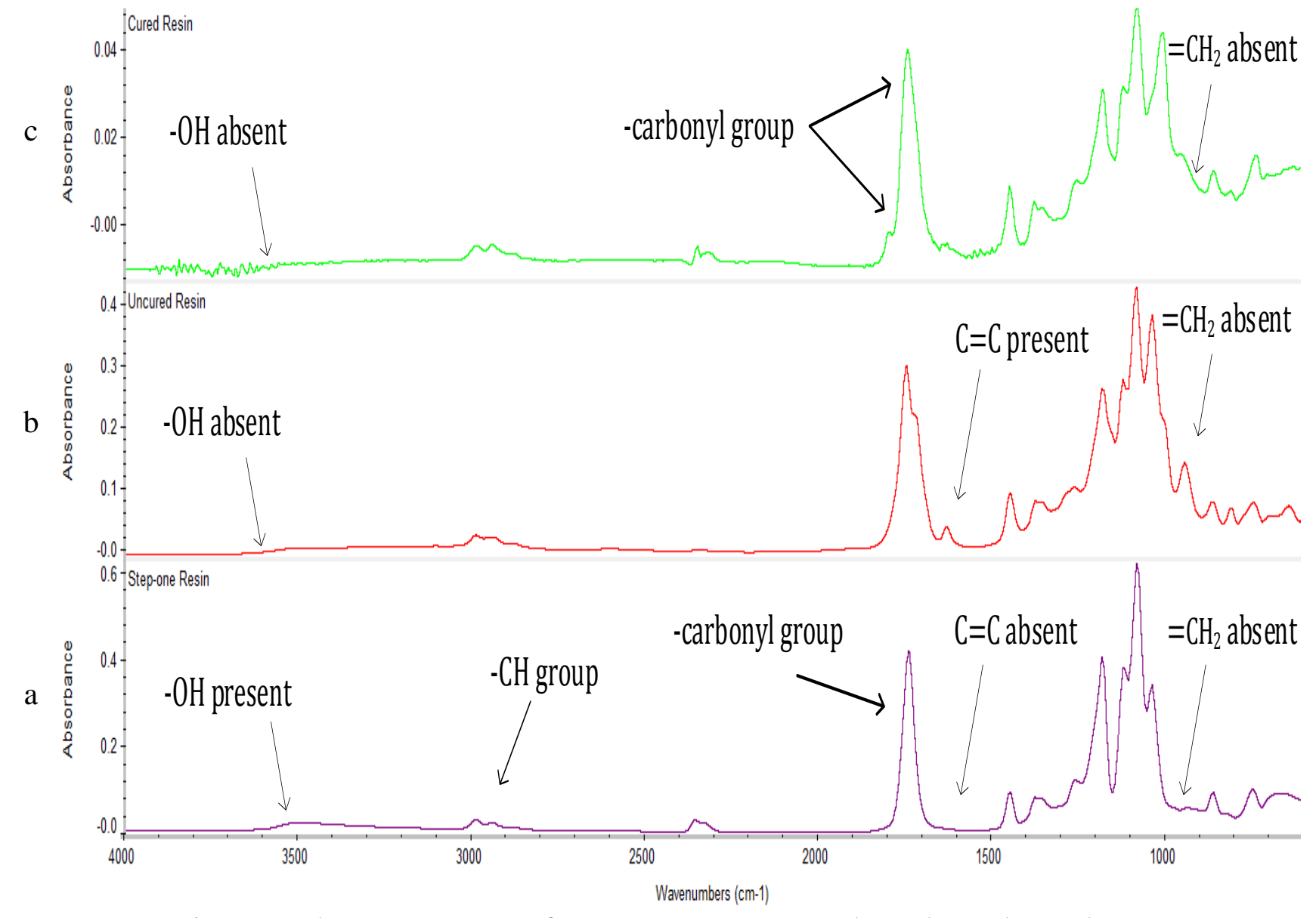

Figure 5, The FTIR spectra of step-one (a), step-two (b) and cured samples (c). 


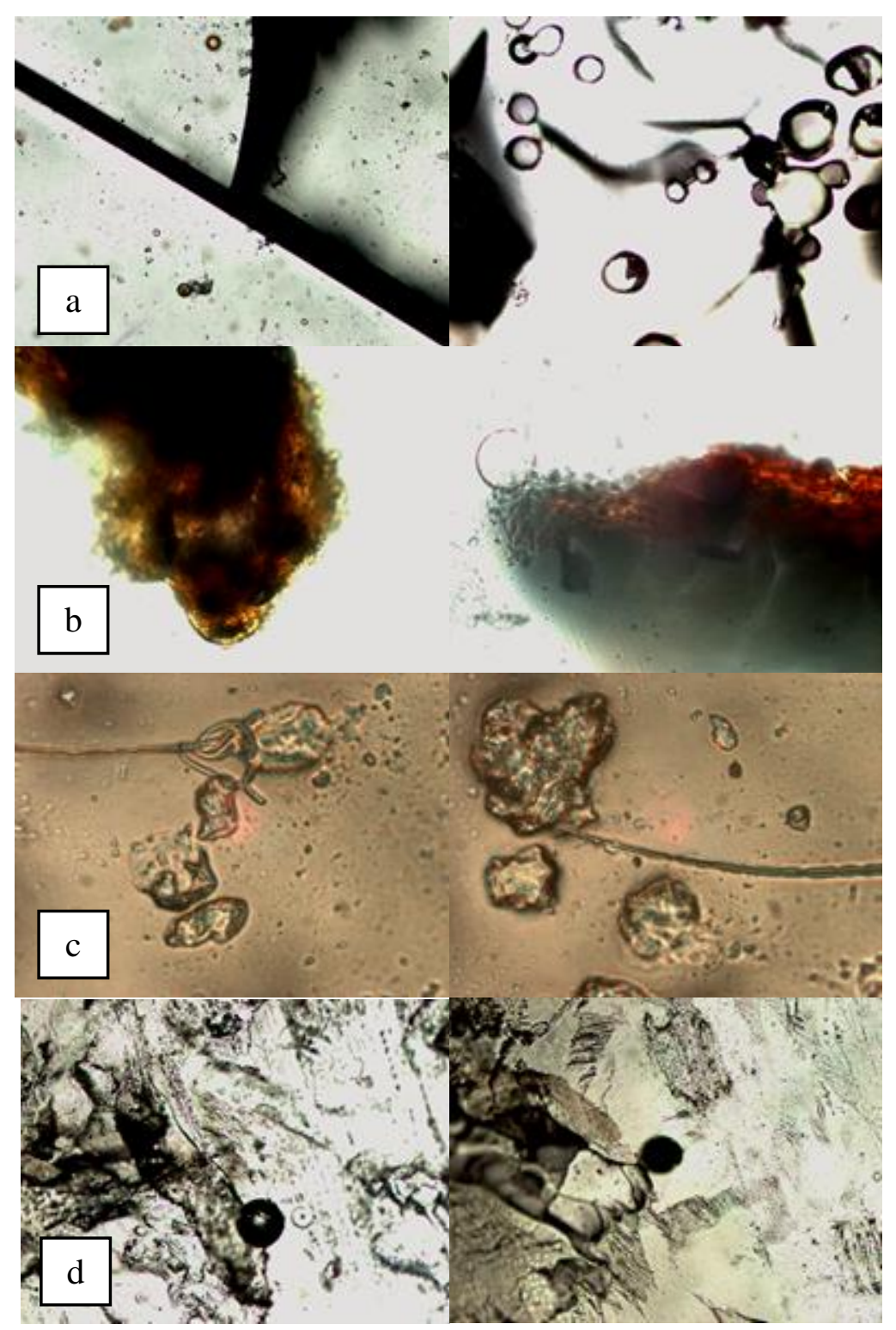

Figure 6, effect of curing method on distribution and propagation of bubbles and cracks-100X 

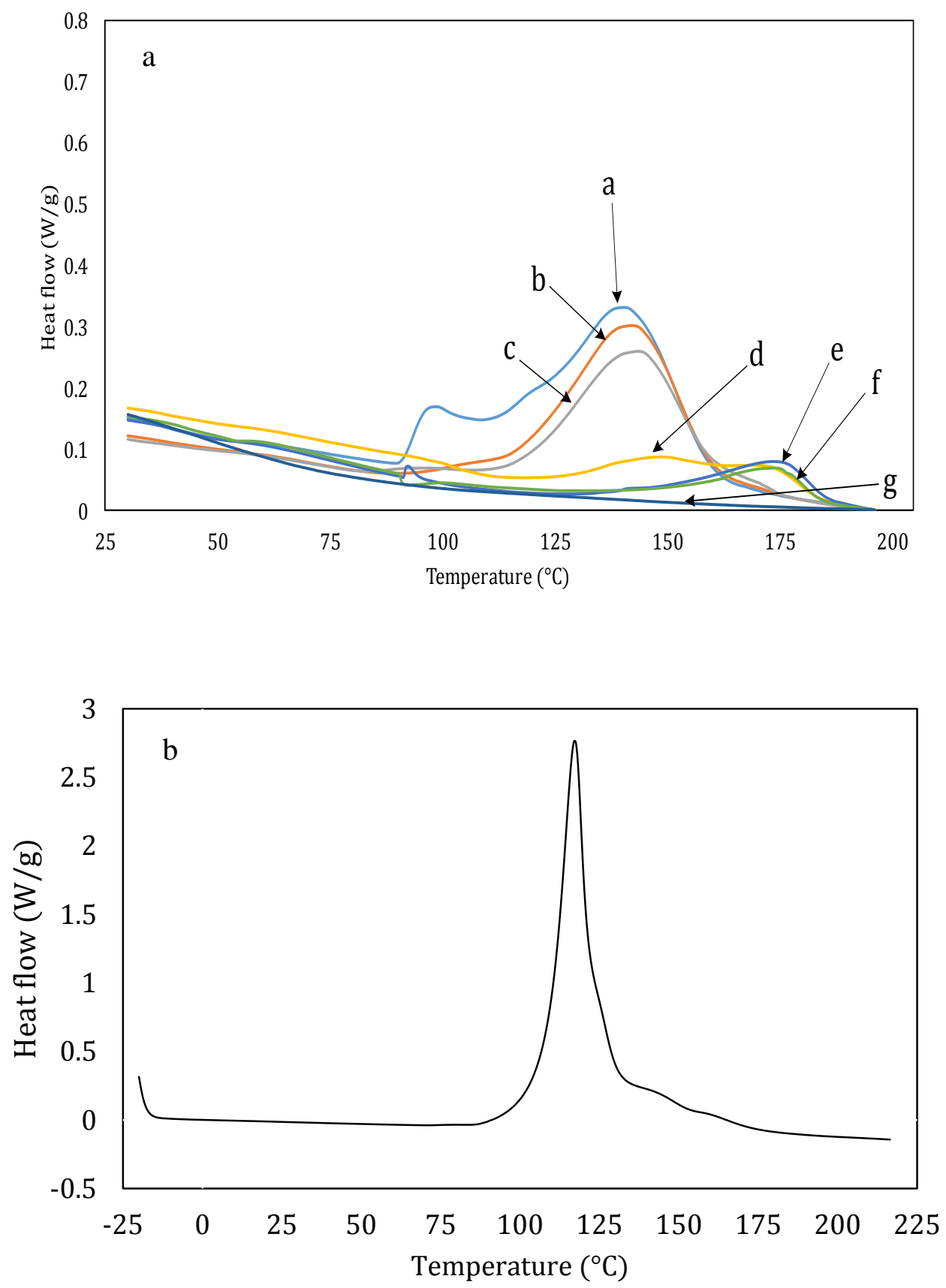

Figure 7, a) DSC curves for residual exotherms for samples cured for 20 minutes at $90^{\circ} \mathrm{C}($ a), $100^{\circ} \mathrm{C}(\mathrm{b}), 110^{\circ} \mathrm{C}(\mathrm{c}), 120^{\circ} \mathrm{C}(\mathrm{d}), 130^{\circ} \mathrm{C}(\mathrm{e}), 140^{\circ} \mathrm{C}(\mathrm{f})$ and $\left.150^{\circ} \mathrm{C}(\mathrm{g}) \mathrm{b}\right) \mathrm{DSC}$ curve for unreacted xylitol-LA at a heat rate of $10^{\circ} \mathrm{C} / \mathrm{min}$ in the heat range of -20 to $220^{\circ} \mathrm{C} / \mathrm{min}$ 


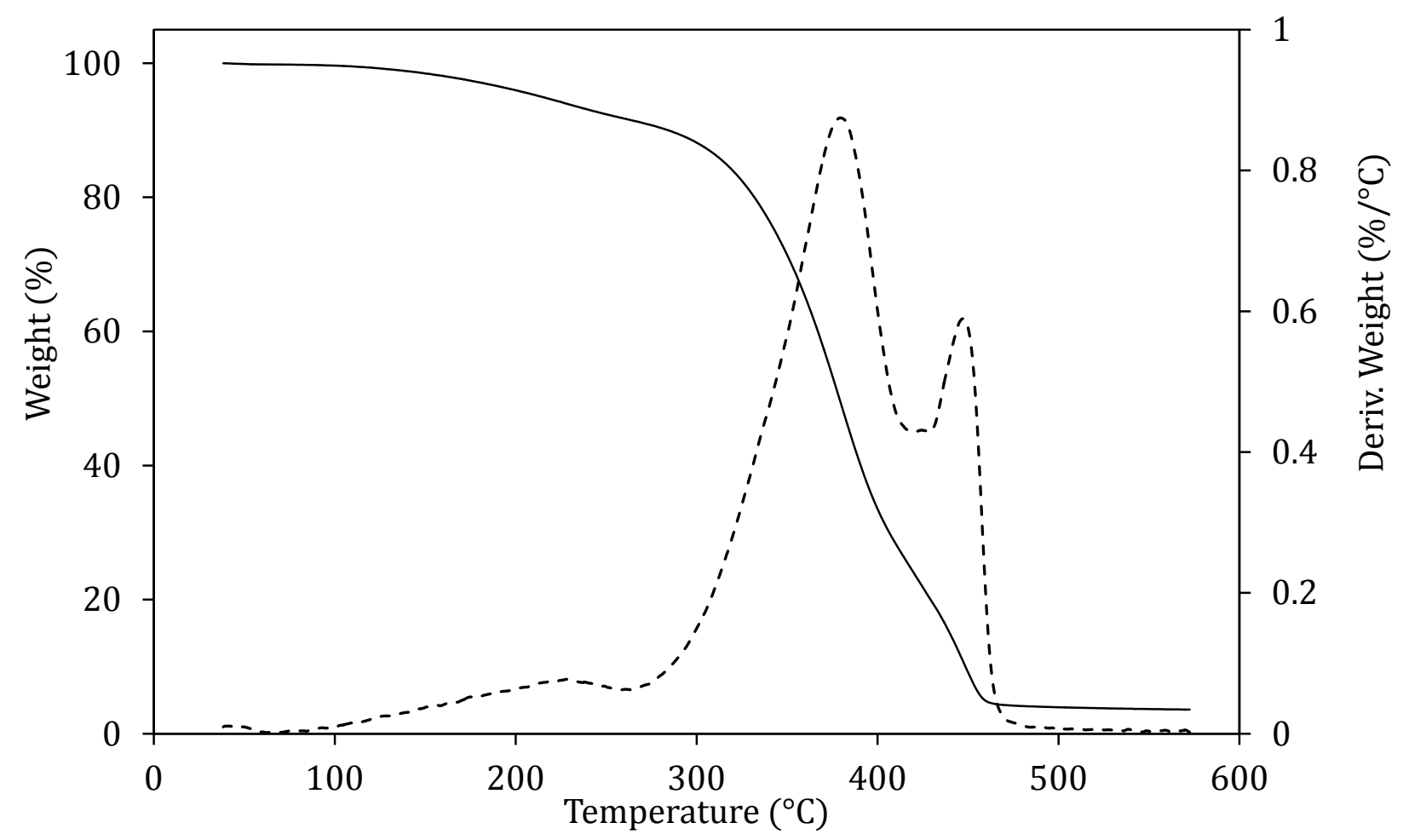

Figure 8, TGA curves for cured resin, solid-line presents Weight (\%) and dashed-typed pattern shows Derivative Weight $\left(\% /{ }^{\circ} \mathrm{C}\right)$ 

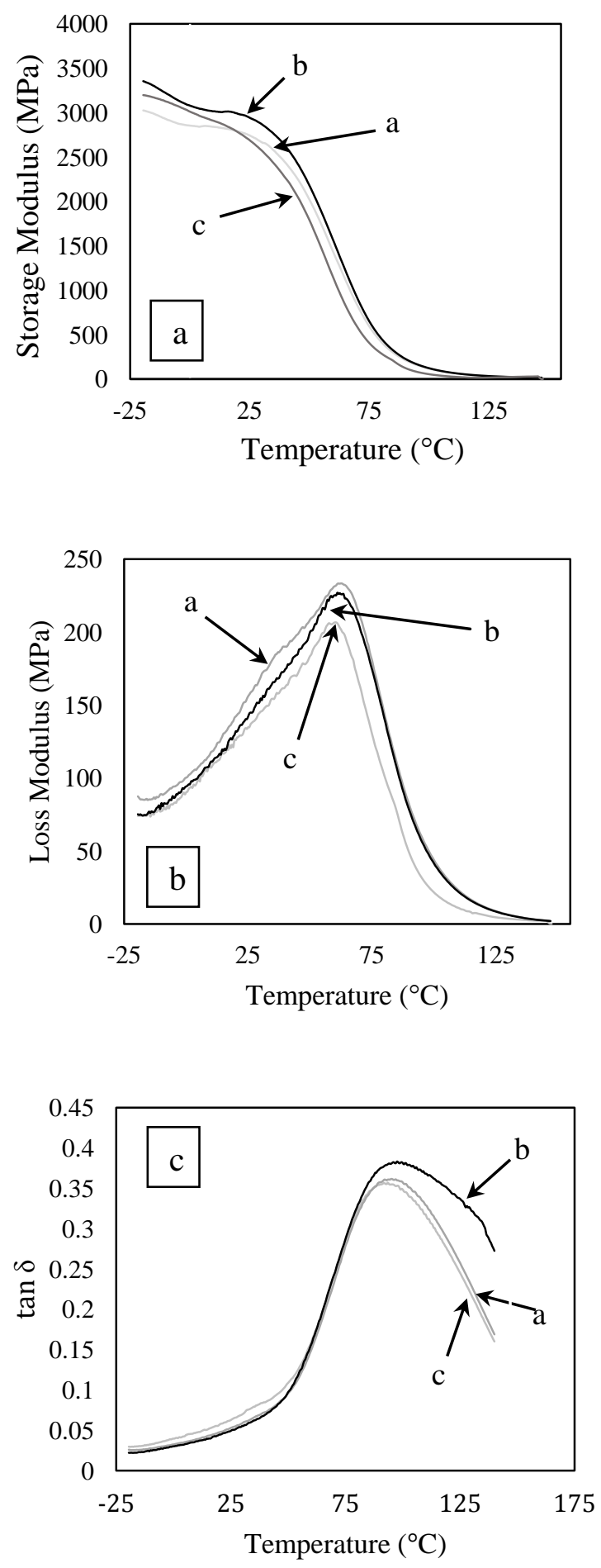

Figure 9, DMA curves ((a) Storage modulus, (b) Loss modulus and (c) tan $\delta)$ for samples cured via different methods, $a, b$ and $c$ ). 


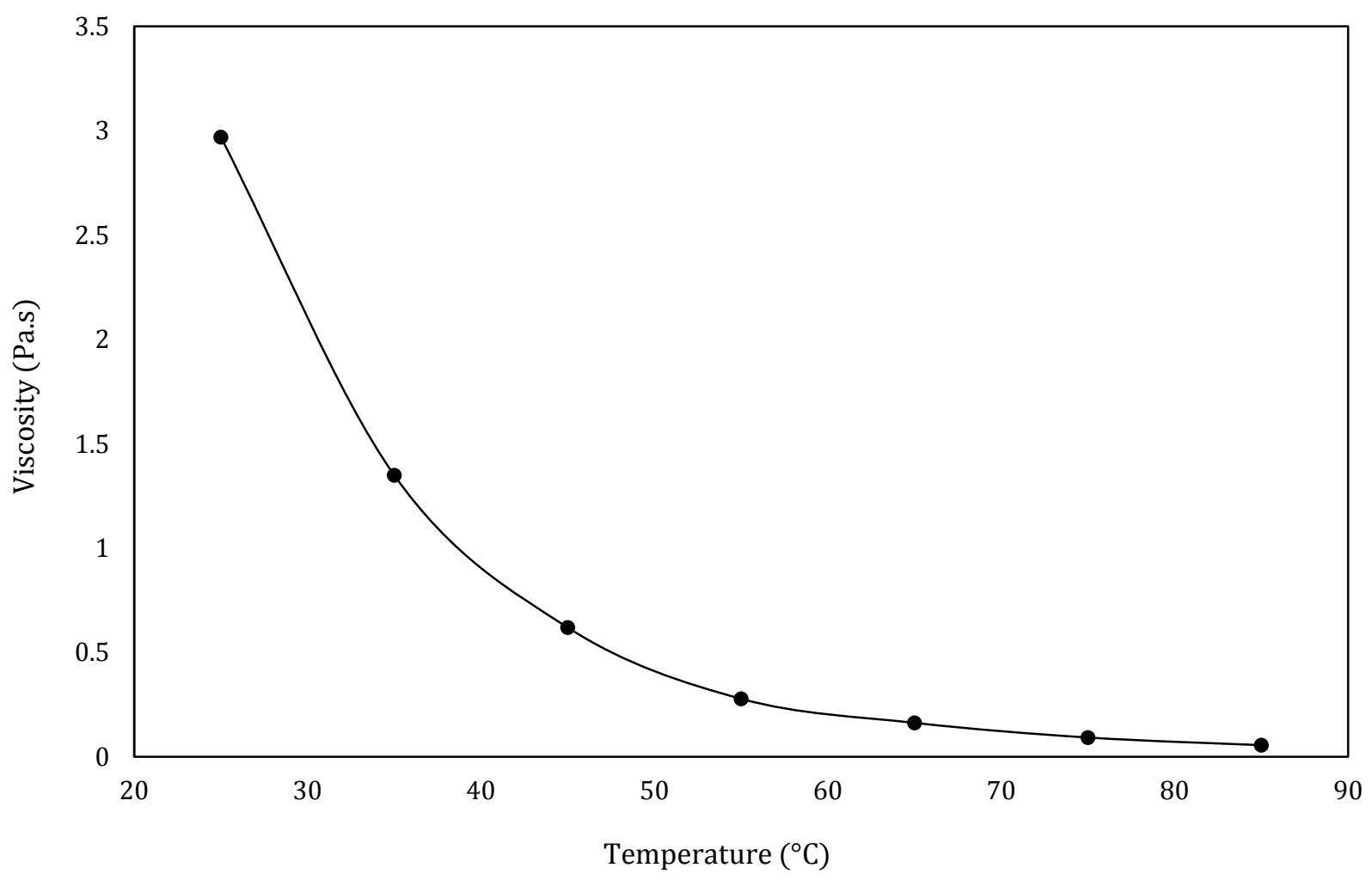

Figure 10, viscosity of resin as a function of temperature 

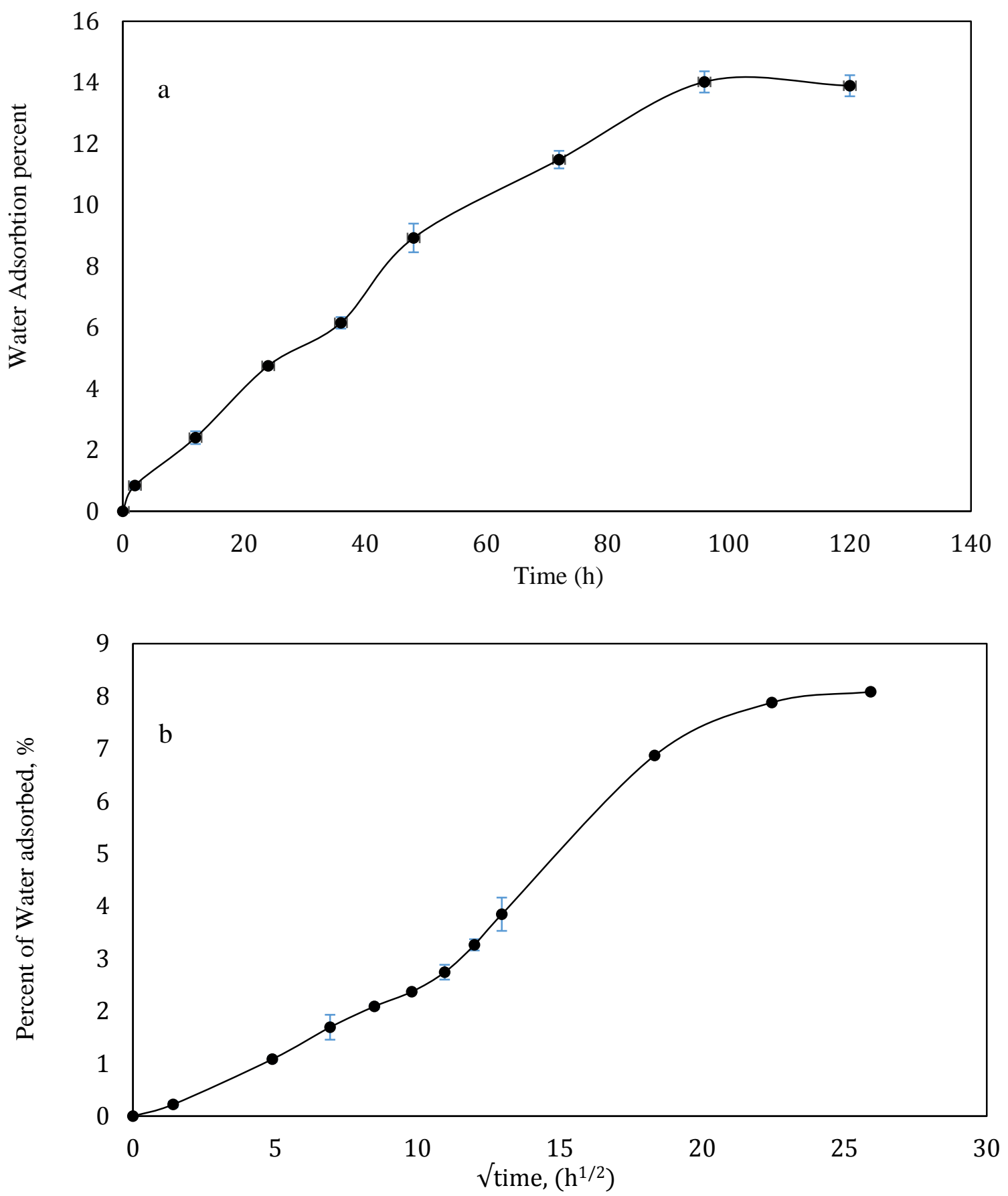

Figure 11, a) percent of absorbed water versus immersing time at $50^{\circ} \mathrm{C}$, b) long-term immersion procedure water adsorption; reported as a function of the square root of immersion time 
Table 1, Assignment of peaks from ${ }^{13} \mathrm{C}-\mathrm{NMR}$

\begin{tabular}{|c|c|c|c|}
\hline Peak & $\begin{array}{c}\text { Exp Chem shift } \\
(\mathrm{ppm})\end{array}$ & $\begin{array}{l}\text { Obs Chem } \\
\text { Shift (ppm) }\end{array}$ & Assignment \\
\hline $\mathrm{A}_{1}$ & 21.5 & 20.3 & $\mathrm{CH}_{3}-\mathrm{Hydroxyl}$ terminated \\
\hline $\mathrm{A}_{2}$ & 16.5 & $16.6-16.7$ & $\mathrm{CH}_{3}$ of lactic acid $-\mathrm{C}(=\mathrm{O})-\mathrm{O}-$ \\
\hline $\mathrm{A}_{3}$ & 17.9 & $17.8-18.1$ & $\mathrm{CH}_{3}$ of methacrylate \\
\hline $\mathrm{B}_{1}$ & 65.6 & 66.6 & $\mathrm{CH}-\mathrm{C}(=\mathrm{O})-\mathrm{OH}-\mathrm{CH}_{3}$ \\
\hline $\mathrm{B}_{2}$ & 70.6 & $70-71$ & $\mathrm{CH} \vdash \mathrm{C}(=0)-\mathrm{O}-\mathrm{CH}_{3}$ \\
\hline $\mathrm{B}_{3}$ & 70.3 & $70-71$ & $\mathrm{CH} \vdash \mathrm{C}(=\mathrm{O}-\mathrm{O})-\mathrm{O}-\mathrm{CH}_{3}$ \\
\hline $\mathrm{B}_{4}$ & 68.7 & 68.7 & $\mathrm{CH} \vdash \mathrm{CH}_{2}-\mathrm{O}-\mathrm{CH}$ \\
\hline $\mathrm{B}_{5}$ & 70.2 & 70.2 & $\mathrm{CH} \vdash \mathrm{CH}-\mathrm{CH}-\mathrm{O}$ \\
\hline $\mathrm{B}_{\sim 6}$ & 70.4-70.7 & $71-71$ & $\mathrm{CH} \vdash$ End-capped main chain \\
\hline $\mathrm{C}_{1}$ & 170.8 & 169.9 & $\mathrm{C}=\mathrm{O} \vdash$ Main chain - \\
\hline $\mathrm{C}_{2}$ & 169.0 & 169.6 & $\mathrm{C}=\mathrm{O} \vdash \mathrm{O}\left(\mathrm{CH}_{2}\right)-\mathrm{CH}$ \\
\hline $\mathrm{C}_{3}$ & 167.2 & 166.57 & $C=0-0-C$ \\
\hline $\mathrm{D}_{1}$ & 125.2 & $126-127$ & $\mathrm{CH}_{2}=\mathrm{C}-$ \\
\hline $\mathrm{E}_{1}$ & 136.0 & $135-136$ & $\mathrm{C}=\mathrm{CH}_{2}-\mathrm{C}-\mathrm{CH}_{3}$ \\
\hline
\end{tabular}


Table 2, Thermal-Mechanical Characterization Results of the Resin

\begin{tabular}{|c|c|c|c|c|}
\hline \multicolumn{5}{|l|}{ DSC } \\
\hline & \multicolumn{3}{|c|}{ Heat of exotherm for uncured resin $(\mathrm{J} / \mathrm{g})$} & 275.5 \\
\hline & \multicolumn{3}{|c|}{ Curing temperature interval } & $00-140^{\circ} \mathrm{C}$ \\
\hline & \multicolumn{2}{|c|}{ Heat of exotherm for cured resin $(\mathrm{J} / \mathrm{g})$ at $150^{\circ} \mathrm{C}$} & \multicolumn{2}{|c|}{0} \\
\hline & \multicolumn{2}{|c|}{ Peak temperature } & \multicolumn{2}{|c|}{$117.25^{\circ} \mathrm{C}$} \\
\hline & \multicolumn{2}{|l|}{ Onset temperature } & \multicolumn{2}{|c|}{$108^{\circ} \mathrm{C}$} \\
\hline \multicolumn{5}{|l|}{ DMA } \\
\hline & $\tan \delta$ peak $\left(\mathrm{T}_{\mathrm{g}}{ }^{\circ} \mathrm{C}\right)$ & $\begin{array}{c}\text { method a } \\
93^{\circ} \mathrm{C}\end{array}$ & $\begin{array}{c}\text { method b } \\
98^{\circ} \mathrm{C}\end{array}$ & $\begin{array}{c}\text { method c } \\
95^{\circ} \mathrm{C}\end{array}$ \\
\hline & Storage modulus $(\mathrm{MPa})$ at $25^{\circ} \mathrm{C}$ & $2739 \pm 102$ & $2938 \pm 101$ & $2875 \pm 101$ \\
\hline & Loss modulus $(\mathrm{MPa})$ at $25^{\circ} \mathrm{C}$ & $171 \pm 14.6$ & $155.8 \pm 14.5$ & $141.7 \pm 15.2$ \\
\hline \multicolumn{5}{|l|}{ TGA } \\
\hline & \multicolumn{2}{|c|}{ Degradation temperature range } & \multicolumn{2}{|c|}{$170-462^{\circ} \mathrm{C}$} \\
\hline & \multicolumn{2}{|c|}{ Degradation temperature at $10 \mathrm{wt} \%$ loss $\left({ }^{\circ} \mathrm{C}\right)$} & \multicolumn{2}{|c|}{$269^{\circ} \mathrm{C}$} \\
\hline & \multicolumn{2}{|c|}{ Maximum degradation $\left({ }^{\circ} \mathrm{C}\right)$} & \multicolumn{2}{|c|}{$380^{\circ} \mathrm{C}$} \\
\hline & \multicolumn{2}{|l|}{ Second derivative peak $\left({ }^{\circ} \mathrm{C}\right)$} & \multicolumn{2}{|c|}{$435^{\circ} \mathrm{C}$} \\
\hline
\end{tabular}




\section{References}

1. Mashouf Roudsari, G., A.K. Mohanty, and M. Misra, Study of the curing kinetics of epoxy resins with biobased hardener and epoxidized soybean oil. ACS Sustainable Chemistry \& Engineering, 2014. 2(9): p. 2111-2116.

2. Liu, K., S.A. Madbouly, and M.R. Kessler, Biorenewable thermosetting copolymer based on soybean oil and eugenol. European Polymer Journal, 2015. 69: p. 16-28.

3. Xiong, Z., et al., The properties of poly (lactic acid)/starch blends with a functionalized plant oil: Tung oil anhydride. Carbohydrate polymers, 2013. 95(1): p. 77-84.

4. Auvergne, R., et al., Biobased thermosetting epoxy: present and future. Chemical Reviews, 2013. 114(2): p. 1082-1115.

5. Bakare, F.O., et al., Synthesis and characterization of bio-based thermosetting resins from lactic acid and glycerol. Journal of Applied Polymer Science, 2014. 131(13).

6. Ma, S., et al., Bio-based epoxy resin from itaconic acid and its thermosets cured with anhydride and comonomers. Green Chemistry, 2013. 15(1): p. 245-254.

7. Lunt, J., Large-scale production, properties and commercial applications of polylactic acid polymers. Polymer degradation and stability, 1998. 59(1): p. 145-152.

8. Martinez, F.A.C., et al., Lactic acid properties, applications and production: a review. Trends in food science \& technology, 2013. 30(1): p. 70-83.

9. Jiménez, A., M. Peltzer, and R. Ruseckaite, Poly (lactic Acid) Science and Technology: Processing, Properties, Additives and Applications. 2014: Royal Society of Chemistry.

10. Raquez, J.M., et al., Thermosetting (bio)materials derived from renewable resources: A critical review. Progress in Polymer Science, 2010. 35(4): p. 487-509.

11. Komkov, M., V. Tarasov, and V. Kuznetsov, The influence of epoxide resin viscosity on impregnation of fiber reinforcement. Polymer Science Series D, 2015. 8(4): p. 292-295.

12. Han, G.-S., et al., Viscosity, Micro-Leakage, Water Solubility and Absorption in a Resin-based Temporary Filling Material. Indian Journal of Science and Technology, 2015. 8(25).

13. Liang, G. and K. Chandrashekhara, Cure kinetics and rheology characterization of soy-based epoxy resin system. Journal of applied polymer science, 2006. 102(4): p. 3168-3180.

14. Oksman, K., M. Skrifvars, and J.-F. Selin, Natural fibres as reinforcement in polylactic acid (PLA) composites. Composites science and technology, 2003. 63(9): p. 1317-1324.

15. Wambua, P., J. Ivens, and I. Verpoest, Natural fibres: can they replace glass in fibre reinforced plastics? composites science and technology, 2003. 63(9): p. 1259-1264.

16. Qin, L., et al., Mechanical and thermal properties of poly (lactic acid) composites with rice straw fiber modified by poly (butyl acrylate). Chemical Engineering Journal, 2011. 166(2): p. 772-778.

17. Garlotta, D., A literature review of poly (lactic acid). Journal of Polymers and the Environment, 2001. 9(2): p. 63-84.

18. Sutivisedsak, N., et al., Evaluation of cotton byproducts as fillers for poly (lactic acid) and low density polyethylene. Industrial Crops and Products, 2012. 36(1): p. 127-134.

19. Kabir, M., et al., Chemical treatments on plant-based natural fibre reinforced polymer composites: An overview. Composites Part B: Engineering, 2012. 43(7): p. 2883-2892.

20. Liu, L., et al., Ultrasonic treatment of aramid fiber surface and its effect on the interface of aramid/epoxy composites. Applied Surface Science, 2008. 254(9): p. 2594-2599. 
21. Bozaci, E., et al., Effects of the atmospheric plasma treatments on surface and mechanical properties of flax fiber and adhesion between fiber-matrix for composite materials. Composites Part B: Engineering, 2013. 45(1): p. 565-572.

22. Makadia, H.K. and S.J. Siegel, Poly lactic-co-glycolic acid (PLGA) as biodegradable controlled drug delivery carrier. Polymers, 2011. 3(3): p. 1377-1397.

23. Bakare, F.O., et al., Thermomechanical properties of bio-based composites made from a lactic acid thermoset resin and flax and flax/basalt fibre reinforcements. Composites Part A: Applied Science and Manufacturing, 2015.

24. Åkesson, D., et al., Synthesis and characterization of a lactic acid-based thermoset resin suitable for structural composites and coatings. Journal of applied polymer science, 2010. 115(1): p. 480486.

25. Bakare, F.O., et al., Synthesis and characterization of unsaturated lactic acid based thermoset bio-resins. European Polymer Journal, 2015. 67: p. 570-582.

26. Sakai, R., et al., Fabrication of Polylactide-Based Biodegradable Thermoset Scaffolds for Tissue Engineering Applications. Macromolecular Materials and Engineering, 2013. 298(1): p. 45-52.

27. Chang, S., et al., Synthesis of polylactide-based thermoset resin and its curing kinetics. Polymer International, 2012. 61(10): p. 1492-1502.

28. Åkesson, D., et al., Thermoset lactic acid-based resin as a matrix for flax fibers. Journal of Applied Polymer Science, 2011. 119(5): p. 3004-3009.

29. Moon, S.-I., et al., Synthesis and properties of high-molecular-weight poly (L-lactic acid) by melt/solid polycondensation under different reaction conditions. High Performance Polymers, 2001. 13(2): p. S189-S196.

30. Murillo, E.A., P.P. Vallejo, and B.L. López, Effect of tall oil fatty acids content on the properties of novel hyperbranched alkyd resins. Journal of Applied Polymer Science, 2011. 120(6): p. 31513158.

31. Xiao, L., et al., Bio-based green composites with high performance from poly (lactic acid) and surface-modified microcrystalline cellulose. Journal of Materials Chemistry, 2012. 22(31): p. 15732-15739.

32. Adekunle, K., D. Åkesson, and M. Skrifvars, Synthesis of reactive soybean oils for use as a biobased thermoset resins in structural natural fiber composites. Journal of applied polymer science, 2010. 115(6): p. 3137-3145.

33. Hisham, S.F., et al., Blends of LNR with unsaturated polyester resin from recycled PET: comparison of mechanical properties and morphological analysis with the optimum blend by commercial resin. Sains Malaysiana, 2011. 40(7): p. 729-735.

34. Gledhill, R., et al., Relationship between mechanical properties of and crack progogation in epoxy resin adhesives. Polymer, 1978. 19(5): p. 574-582.

35. Phillips, D., J. Scott, and M. Jones, Crack propagation in an amine-cured epoxide resin. Journal of Materials Science, 1978. 13(2): p. 311-322.

36. Carfagna, C., E. Amendola, and M. Giamberini. Liquid crystalline epoxy resins. in Liquid Crystalline Polymers: Proceedings of the International Workshop on Liquid Crystalline Polymers, WLCP 93, Capri, Italy, June 1-4 1993. 2013. Elsevier.

37. Heinrich, C., et al., The role of curing stresses in subsequent response, damage and failure of textile polymer composites. Journal of the Mechanics and Physics of Solids, 2013. 61(5): p. 12411264.

38. Pereira, A.A.C. and J.R.M. d'Almeida, Effect of the hardener to epoxy monomer ratio on the water absorption behavior of the DGEBA/TETA epoxy system. Polímeros, 2016. 26(1): p. 30-37.

39. Allen, K.A., Processing of Thermoplastic Composites. Polymer and Composites Processing, 2012: p. 1-10. 
40. Campbell Jr, F.C., Manufacturing processes for advanced composites. 2003: Elsevier.

41. Mohan, T., M. Ramesh Kumar, and R. Velmurugan, Rheology and curing characteristics of epoxy-clay nanocomposites. Polymer International, 2005. 54(12): p. 1653-1659.

42. Vergnaud, J.-M. and J. Bouzon, Cure of thermosetting resins: modelling and experiments. 2012: Springer Science \& Business Media.

43. ASTM D570-98(2010)e1, Standard Test Method for Water Absorption of Plastics, . ASTM International, West Conshohocken, PA, 2010, www.astm.org, 2010. 